\title{
Miscibility, Morphology, and Thermal Characterization of an Acrylic/Styrenic Blend System. Poly(cyclohexyl methacrylate) and Poly $(\alpha$-methyl styrene)
}

\author{
Li Ling CHANG and Ea Mor WoO ${ }^{\dagger}$ \\ Department of Chemical Engineering, \\ National Cheng Kung University, \\ Tainan 701-01, Taiwan
}

(Received January 31, 2000; Accepted September 23, 2000)

\begin{abstract}
Miscibility in binary polymer mixtures involving styrenic polymers and acrylics has been rare. Thermal analysis, optical and scanning electron microscopy were performed to reveal complete miscibility in the blend system of poly $(\alpha$-methyl styrene) (P $\alpha$ MS) and poly (cyclohexyl methacrylate) (PCHMA). Within the wide range of molecular weight (MW) of $\mathrm{P} \alpha \mathrm{MS}$ (several thousands up to a high MW of $400000 \mathrm{~g} \mathrm{~mol}^{-1}$ ), all P $\alpha$ MS/PCHMA mixtures were found to be completely miscible, with phase separation at quite high lower-critical-solution-temperatures (LCST). The FT-IR characterization did not reveal any specific intermolecular interactions between the pairs. Miscibility in blends of styrenic polymers with acrylic polymers is rare and not commonly seen. Structural effects on the phase behavior in blends of styrenic polymer and acrylic polymers are briefly discussed.

KEY WORDS Poly $(\alpha$-methyl styrene)/Poly(cyclohexyl methacrylate) / Miscibility / Blend /
\end{abstract}

Polymer miscibility in blends involving homopolymeric polystyrene (PS) has not been common. It is easy to understand because a styrenic polymer, such as PS, does not possess any functional groups that are capable of interacting specifically with other polymer molecules. As a result, it is not easy to discover miscible blend involving homopolymeric PS. Two well-known exceptions exist, in which two classical blends comprising PS and ether-containing polymers are known to be miscible. One of the most studied is the blend system of PS with poly(1,4-dimethyl-p-phenylene oxide) (PPO) and its miscibility has been demonstrated since early time. ${ }^{1-3}$ Another notable example of miscible blends comprising PS and an ether-containing polymer is given by the classical PS/poly(vinyl methyl ether) (PVME) system. ${ }^{4-6}$ Unlike the well-established miscibility in PS/PPO, the true phase behavior in the PS/PVME system has been more controversial and somewhat inconclusive owing to its peculiar $T_{\mathrm{g}}$ behavior and significant broadening.

Interestingly, although PS can be miscible with at least the above-mentioned ether-containing polymers, blends of PS with carbonyl-containing or methacrylic polymers are mostly immiscible. The literature contains no reports that PS can be miscible with any carbonylcontaining polymers. Additionally, homopolymeric PS is generally immiscible with any of acrylic or methacrylic polymers. Most blends of PS with acrylic or methacrylic polymers are phase-separated. Blends of PS with poly(methyl methacrylate) (PMMA) have been more often studied, which are known to be immiscible (noncompatible) as reported in an early paper. ${ }^{7}$ Although by manipulation of kinetic process of solvent removal during blend preparation (e.g., freeze-drying, etc.), the PS/ PMMA mixture may be temporarily locked into homogeneous phase structure showing an apparent single- $T_{\mathrm{g}}$, the blend is a two-phase mixture at thermodynamic equilibrium. A styrenic/acrylic blend system that is clos- est to being classified as a quasi-homogeneous mixture is demonstrated by the case of PS/poly(cyclohexyl methacrylate) (PCHMA) blend. At low molecular weights of PS (e.g., $\left.M_{\mathrm{n}}=90000 \mathrm{~g} \mathrm{~mol}^{-1}\right)$, the PS/PCHMA blend system has been pronounced to be miscible in the literature. ${ }^{8,9}$ Miscibility in PS/PCHMA has been assumed from the "transparent-looking" of the blends and exhibition of gross phase separation upon heating at about 220 $-240^{\circ} \mathrm{C}$ because it is difficult to assess the phase behavior owing to almost identical $T_{\mathrm{g}}$ of the constituent polymers. ${ }^{9}$ It must be noted here that micro-domains $(0.1-$ $0.3 \mu \mathrm{m}$ ) in polymers are optically clear beyond the resolution limit of optical microscopy. Thus, true thermodynamic phase behavior of the PS/PCHMA blend is complex and beyond the scope of this paper; but it is of less debate that PS/PCHMA blend is miscible for low MW's of PS. Similar dependence of phase behavior on the molecular weight (MW) has also been extensively reported for the classical PS/PVME blend system. ${ }^{4-6}$

A slight change in the structure of the styrenic polymer may result in the phase behavior of such a blend going closer to or farther away from miscibility. For examples, poly(4-methyl styrene) (P4MS, with the methyl group at 4-phenyl position) is a styrenic polymer. Note that P4MS is similar to PS, except that a methyl group is attached to the 4-phenyl ring position. Blend of P4MS/ PCHMA has been found to be miscible according to an earlier study, ${ }^{10}$ with a lower critical solution temperature (LCST) at $c a .250^{\circ} \mathrm{C}$. To understand main factors in blend miscibility involving PS, it was necessary to investigate relationship between structure and phase behavior in PS blends. In this study, the structure of polystyrene was altered by introducing a methyl group onto the $\alpha$-position, i.e., PS was replaced by poly $(\alpha$-methyl styrene). Relevant experiments other than thermal analysis were performed and results analyzed with care. Phase behavior and structural effects in blends compris-

\footnotetext{
${ }^{\dagger}$ To whom correspondence should be addressed (Fax: +886-6-234-4496, Phone: +886-6-275-7575 Ext.62670, E-mail: emwoo@mail.ncku. edu.tw).
} 
ing a styrenic polymer ( $\mathrm{P} \alpha \mathrm{MS})$ and a methacrylic polymer (PCHMA) blends were investigated. Dependence on the structure of the constituent polymers is discussed. In addition, we were aware of possible effects of MW on the phase behavior. In this work, we used a wide range of $\mathrm{P} \alpha \mathrm{SM}$ MW from 7500 to nearly $400000 \mathrm{~g} \mathrm{~mol}^{-1}$. Effects of variation of MW of PCHMA on phase behavior of the $\mathrm{P} \alpha \mathrm{SM} / \mathrm{PCHMA}$ blend, if any, could be expected to be similar; thus, it was not doubly examined.

\section{EXPERIMENTAL}

\section{Materials}

Poly(cyclohexyl methacrylate) (PCHMA) was supplied by Scientific Polymers Product, Inc. (USA), with an approximate $M_{\mathrm{w}}=65000 \mathrm{~g} \mathrm{~mol}^{-1}(\mathrm{GPC})$, and a $T_{\mathrm{g}}$ of $110^{\circ} \mathrm{C}$. A styrenic polymer, $\operatorname{poly}(\alpha$-methyl styrene) (P $\alpha \mathrm{MS})$, was also obtained from Scientific Polymers Product, Inc. (USA). Two different grades of $\mathrm{P} \alpha \mathrm{MS}$ (low-molecularweight $\mathrm{LMW}=7500 \mathrm{~g} \mathrm{~mol}^{-1}$ and high-molecular-weight $\mathrm{HMW}=398000 \mathrm{~g} \mathrm{~mol}^{-1}$ ) (gel permeation chromatograph, GPC) were used for comparison. The LMWgrade $\mathrm{P} \alpha \mathrm{MS}\left(M_{\mathrm{w}}=7500 \mathrm{~g} \mathrm{~mol}^{-1}\right)$ is of a wide polydispersity index (PI), with a relatively low $T_{\mathrm{g}}=40^{\circ} \mathrm{C}$. The HMW-grade P $\alpha \mathrm{MS}$, with $M_{\mathrm{n}}=M_{\mathrm{w}}=398400 \mathrm{~g} \mathrm{~mol}^{-1}$ and a narrow distribution of $\mathrm{PI}=1.04$, possesses a quite high $T_{\mathrm{g}}$ at $174^{\circ} \mathrm{C}$. The as-received materials were free of additives and were used without further purification. For references, the chemical structures of $\mathrm{P} \alpha \mathrm{MS}$ and PCHMA are shown as following:

\section{P $\alpha$ MS}<smiles>CCC(C)(C)c1ccccc1</smiles>

PCHMA

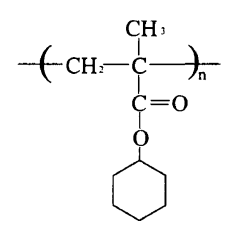

The blend samples in this study were prepared by mixing in solvents followed with solution casting at two different temperatures $\left(25\right.$ or $45^{\circ} \mathrm{C}$ ). Tetrahydrofuran (THF) solvent was used for preparation of all blend samples. The constituent polymers, PCHMA and P $\alpha \mathrm{MS}$, were first weighed respectively and dissolved into THF with continuous stirring. Subsequently, the resulting polymer solution was poured into a flat aluminum or glass mold kept at one of the two designated temperatures $\left(25\right.$ or $\left.45^{\circ} \mathrm{C}\right)$. The solvent in the cast film samples was first vaporized under a hood at controlled temperature, followed by residual solvent removal in a vacuum oven for $48 \mathrm{~h}$ at $50-60^{\circ} \mathrm{C}$. Subsequent vacuum degassing at an even higher temperature of $70-80^{\circ} \mathrm{C}$ was performed on the cast-film samples for two more days to ensure removal of residual solvent.

\section{Apparatus and Procedures}

Differential Scanning Calorimetry (DSC). Glass transition temperatures were measured with a differential scanning calorimeter (Perkin-Elmer DSC-7) equipped with an intracooler and a computer for data acquisition/ analysis. All $T_{\mathrm{g}}$ measurements were made at a scan rate of $20^{\circ} \mathrm{C} \mathrm{min}{ }^{-1} . T_{\mathrm{g}}$ values were taken as the onset of the transition (the change of the specific heat) in the ther- mograms.

Optical Microscopy. A polarized-light microscope (Nikon Optiphot-2, POL) was used. The as-cast blends were spread as thin films on glass slides, dried properly in a temperature-controlled oven before they were examined using the optical microscope. Cloud point measurement of the blends was performed by placing the samples on a microscope heating stage (temperatureprogrammed), with a programmed heating rate of approximately $2^{\circ} \mathrm{C} \mathrm{min}^{-1}$. from room temperature up to $300^{\circ} \mathrm{C}$. Cloud point was registered as the initiation temperature at which separated domains were visible in samples using the maximum magnification of the optical microscope.

Scanning electron microscopy. Morphology (fracture surface) of blends was examined using a scanning electron microscope (SEM) (Model JEOL JXA-840). The THF solution-cast samples, prepared at room temperature and $45^{\circ} \mathrm{C}$, were examined using SEM after preliminary optical microscopy characterization. The blend film samples for scanning electron microscopy were thick enough so that the fracture surface of the thickness (cross section) could be conveniently examined. The fractured blend samples were coated with gold by vapor deposition using a vacuum sputterer.

Infrared Spectroscopy. Fourier-transform infrared spectroscopy (FT-IR Nicolet Magna-560) was used for investigating molecular interactions between the constituents. Spectra were obtained at $4 \mathrm{~cm}^{-1}$ resolution and averages of spectra were obtained from at least 64 scans in the standard wavenumber range of $400-4000 \mathrm{~cm}^{-1}$. All samples were cast as thin films directly on $\mathrm{KBr}$ pellets at $45^{\circ} \mathrm{C}$.

\section{RESULTS AND DISCUSSION}

The as-cast blend films of all compositions (at either 20 or $45^{\circ} \mathrm{C}$ ) were crystal-clear and completely free of any haziness as observed using an optical microscope. The solution casting temperature $\left(20-45^{\circ} \mathrm{C}\right)$ did not seem to influence the result of blend clarity. After preliminary microscopy inspection, DSC analysis was performed on the samples to reveal their thermal transitions. For comparisons based on a uniform thermal history, all DSC thermograms are the results of second runs after quenching from above the prospective blend $T_{\mathrm{g}}$. Figure 1 shows the DSC traces of the PCHMA/P $\alpha$ MS (LMW) blends. The DSC result revealed one apparent $T_{\mathrm{g}}$ in each of the P $\alpha \mathrm{MS} / \mathrm{PCHMA}$ blend samples of different compositions. The thermal transitions for all blend compositions are reasonably sharp and not broadened. The thermal characterization indicated that there was no doubt on the complete miscibility in the PCHMA/P $\alpha \mathrm{MS}$ (LMW) blend. It was necessary to prove that at higher molecular weights of $\mathrm{P} \alpha \mathrm{MS}$, it is still capable of forming a miscible blend with PCHMA. Figure 2 shows the DSC traces of the PCHMA/P $\alpha$ MS (HMW) blends, where HMW designates a high molecular weight of $\mathrm{P} \alpha \mathrm{MS}=$ $398000 \mathrm{~g} \mathrm{~mol}^{-1}$. The thermal characterization of this blend system again revealed one single $T_{\mathrm{g}}$ in each of the different blend compositions. The thermal transitions for all blend compositions, as shown in all DSC traces, are reasonably sharp and not broadened. Miscibility in the 


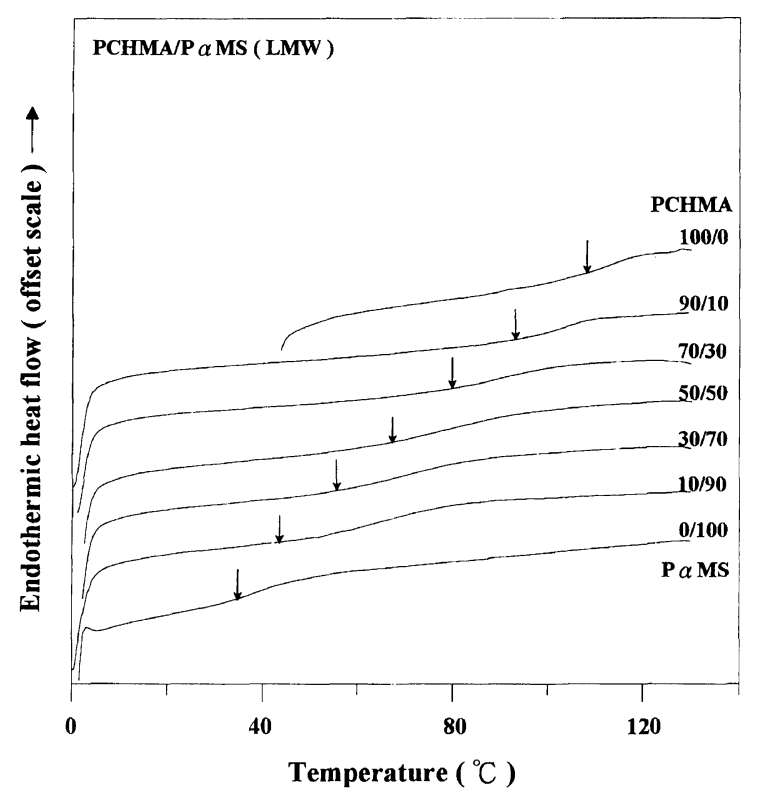

Figure 1. DSC traces of PCHMA/P $\alpha$ MS (LMW) blends, showing one single $T_{\mathrm{g}}$.

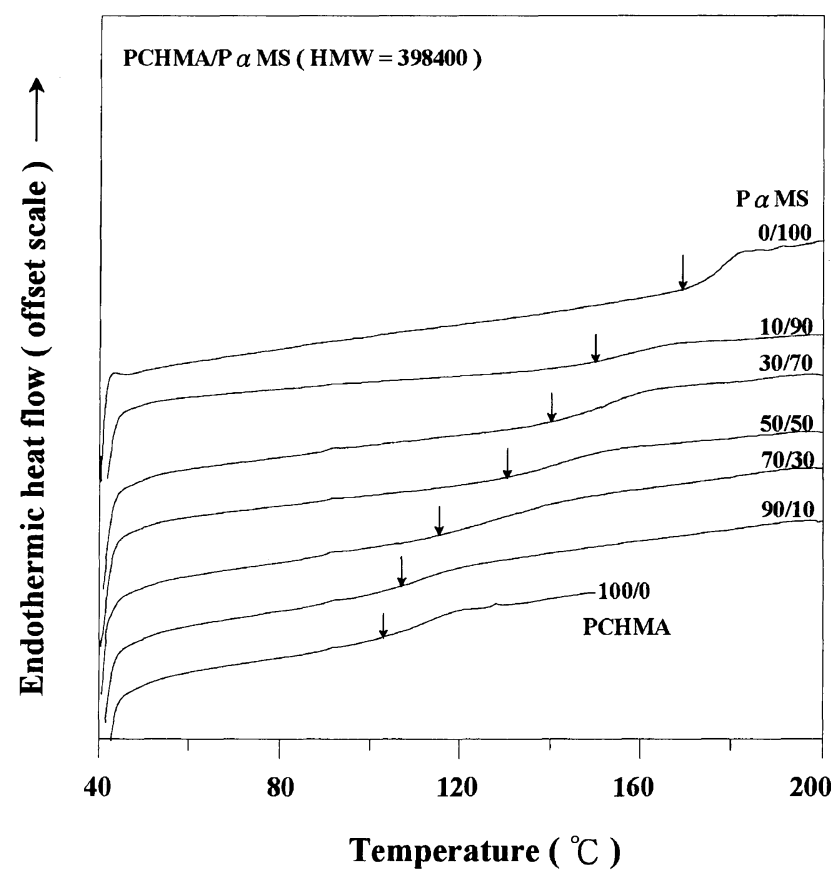

Figure 2. DSC traces of PCHMA/P $\alpha$ MS (HMW) blends, showing one single $T_{\mathrm{g}}$.

PCHMA/P $\alpha$ MS (HMW) as well as PCHMA/P $\alpha$ MS (LMW) blends can be concluded.

Figure 3 shows $T_{\mathrm{g}}$-composition dependence for two miscible PCHMA/P $\alpha$ MS blend systems, in which the molecular weight of $\mathrm{P} \alpha \mathrm{MS}$ is (I) $\mathrm{LMW}=7500 \mathrm{~g} \mathrm{~mol}^{-1}$ and (II) $\mathrm{HMW}=398400 \mathrm{~g} \mathrm{~mol}^{-1}$, respectively. Fitting with conventional $T_{\mathrm{g}}$-composition models was performed. Fitting was performed with the classical $T_{\mathrm{g}}$ model of Fox equation: $1 / T_{\mathrm{g}}=\left(\omega_{1} / T_{\mathrm{g} 1}+\omega_{2} / T_{\mathrm{g} 2}\right)$, or of Gordon-Taylor equation, ${ }^{11}$ i.e., $T_{\mathrm{g}}=\left(\omega_{1} T_{\mathrm{g} 1}+k \omega_{2} T_{\mathrm{g} 2}\right) /\left(\omega_{1}+k\right.$ $\omega_{2}$ ), where $\omega_{i}$ is the mass (weight) fraction of polymer component $i$, and $k$ is a fitting parameter. A value of $k=$



Figure 3. $T_{\mathrm{g}}$-composition dependence for two miscible PCHMA/ $\mathrm{P} \alpha \mathrm{MS}$ blend systems, in which molecular weights of $\mathrm{P} \alpha \mathrm{MS}$ is $(\mathrm{O})$ $\mathrm{LMW}=7500 \mathrm{~g} \mathrm{~mol}^{-1}$, and (O) HMW $=398400 \mathrm{~g} \mathrm{~mol}^{-1}$.

0.52 for the PCHMA/P $\alpha$ MS (HMW) blend and a slightly higher $k=0.8$ for the PCHMA/P $\alpha$ MS (LMW) blend was obtained, suggesting reasonably good phase homogeneity in both miscible blend systems. Note that fitting of the $T_{\mathrm{g}}$ data with the Fox equation was also reasonably good (with only minor deviation) for both systems. The good fit suggests a fine segmental-mixing scale in the blends.

The THF-cast $\left(45^{\circ} \mathrm{C}\right)$ blend samples were visually and optically clear and free of any visibly heterogeneity domains when examined using the optical microscopy $(\mathrm{OM})$. Both as-cast and annealed samples were examined. Annealing at above blend $T_{\mathrm{g}}$ did not lead to difference in its apparent phase structure. In addition, morphology characterization using SEM at higher magnifications was performed to confirm homogeneity in the blends. Figure 4 shows the SEM graphs to illustrate the homogeneity scale in the miscible PCHMA/P $\alpha$ MS(LMW) blend. The SEM characterization revealed no discernible heterogeneity in the solution-cast PCHMA/ $\mathrm{P} \alpha \mathrm{MS}$ blend samples in a wide composition range. Although the SEM characterization revealed absence of sub-micron fine domains, it could not be taken as direct indication of phase miscibility. However, this result did prove that as far as the resolution of SEM was concerned, no discernible micro-heterogeneity existed in the PCHMA/P $\alpha$ MS blend, whose miscibility was already indicated by the glass transition criteria.

Changes of optical clarity (cloud point transition) of the blends with respect to temperature were inspected at step-wise elevating temperatures up to where degradation occurred. Figure 5 shows the cloud-point curves for the miscible PCHMA/P $\alpha$ MS (HMW and LMW) blend. An LCST near $295^{\circ} \mathrm{C}$ is identified for the PCHMA/ $\mathrm{P} \alpha \mathrm{MS} \quad(\mathrm{HMW}=398400)$ blend, and a slightly higher LCST near $310-320^{\circ} \mathrm{C}$ for the PCHMA/P $\alpha$ MS (LMW $=$ 

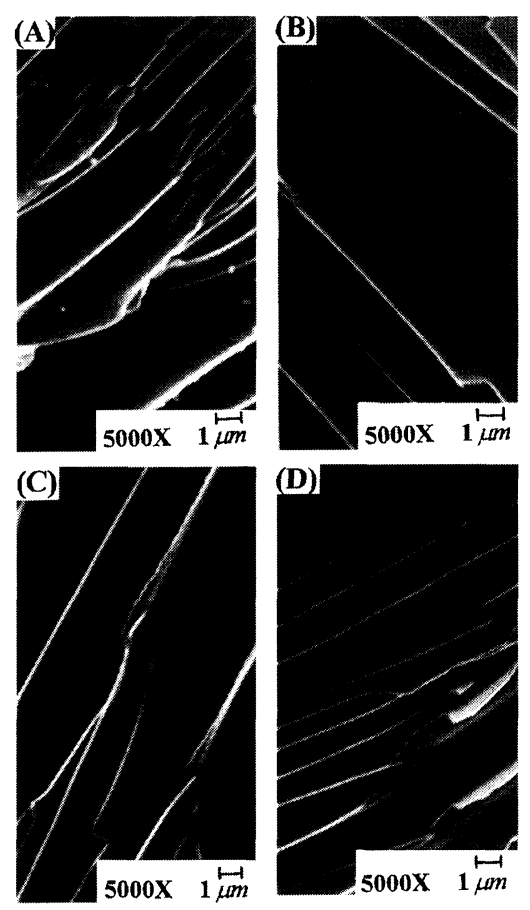

Figure 4. SEM graphs showing the scale of phase homogeneity in the miscible PCHMA/P $\alpha$ MS (LMW) blend: (A) 10/90, (B) 30/70, (C) $50 / 50$, and (D) $70 / 30$.



Figure 5. Cloud-point curves for the miscible PCHMA/P $\alpha \mathrm{MS}$ : (O) LMW P $\alpha$ MS, and (O) HMW P $\alpha$ MS.

7500) blend. For both miscible blend systems, the cloud point phenomenon was observed at quite high temperatures near degradation. The existence of LCST phenomenon in these blends further confirmed that the phase behavior at below the cloud point was homogeneous and miscible. It can be concluded that the PCHMA/ $\mathrm{P} \alpha \mathrm{MS}$ blend is miscible that is accompanied with an LCST phenomenon, with phase separation only at high temperatures near the thermal degradation of the polymers.

Effect of Structure of Styrenic Polymers

It is of interest to compare the phase behavior of
PCHMA/P $\alpha$ MS with another methacrylic/styrenic blend, poly(methyl methacrylate)/P $\alpha \mathrm{MS}$, which has been concluded to be immiscible, except for those with oligomeric-molecular-weight $\mathrm{P} \alpha \mathrm{MS}$ (several thousands), according to an earlier report by Callaghan and Paul. ${ }^{12}$ This study and earlier studies showed that a methacrylic polymer (PCHMA) can be miscible with a range of different styrenic polymers whose structures are varied within a limited range. It is interesting to compare the trend of variation of LCST in the miscible PCHMA/ $\mathrm{P} \alpha \mathrm{MS}$ blend to those for the blends of PCHMA/PS, PCHMA/P4MS reported in earlier papers. ${ }^{10}$ Blends of PCHMA with one of three different styrenic polymers were compared at comparable MW's. The lower critical point of the cloud point curve (phase separation upon heating) is labeled as LCST. The blend system of PS (no methyl group) with PCHMA has been declared to be a miscible system as long as the PS possesses low molecular weights (100000 or lower), ${ }^{8,9}$ which exhibits an LCST of $c a .230^{\circ} \mathrm{C} .{ }^{9} \mathrm{By}$ introducing a methyl group to the repeat unit, e.g., to the 4-position of the PS phenyl ring, P4MS is resulted. In an earlier study, the PCHMA/ P4MS blend has been demonstrated to be miscible within the full composition range, which exhibits an LCST at $c a .-245^{\circ} \mathrm{C} .{ }^{10} \mathrm{P} \alpha \mathrm{MS}$, with the methyl group in the $\alpha$-position, is an isomer to P4MS. This study further proved that PCHMA/P $\alpha$ MS is miscible within the full composition range with the LCST being at quite high temperatures. When directly compared at equivalent molecular weights of the comprising constituents, the P4MS/PCHMA system is miscible with a LCST at 240$250^{\circ} \mathrm{C}$, while PCHMA/P $\alpha \mathrm{MS}$ is also miscible with a higher LCST $\left(\operatorname{LCST}=290-320^{\circ} \mathrm{C}\right)$. The miscibility of the PCHMA/P $\alpha$ MS blend was found to be quite stable, as its phase behavior did not seem to be influenced by different solvents or casting temperature. The slight variation (e.g., methyl substitution) in styrenic polymers does not cause major difference in the blend miscibility behavior in the blends of PCHMA with one of the three styrenic polymers (PS and P4MS in earlier studies, or $\mathrm{P} \alpha \mathrm{MS}$ in this study). However, it does change the temperature of phase separation upon heating (LCST). It has been suggested that a higher LCST in a miscible blend may suggest a better scale of mixing or greater interaction strength if blend systems are compared at comparable MW's and similar structural series (e.g., blends comprising copolymers with varying $\mathrm{A} / \mathrm{B}$ ratios). ${ }^{13}$ Vise versa, a lower LCST most likely indicates a state of phase approaching the border of miscibilityimmiscibility transition.

Possible inter-molecular interactions through specific cites in the constituent polymers (PCHMA or P $\alpha \mathrm{MS}$ ) were examined using FT-IR. For the extensively studied blend of PPO with PS, it has been proposed that a likely site for mutual interaction may involve the phenyl ring of PS and/or ether group of PPO. Similarly, a spectroscopy study on PS/PVME blends prepared in compatible or non-compatible state has concluded that the vibrations most sensitive to change in molecular environment of compatibility are $\mathrm{C}-\mathrm{H}$ out-of-plane bending (at 700 $\left.\mathrm{cm}^{-1}\right)$ in PS and $\mathrm{C}^{-} \mathrm{O}-\mathrm{CH}_{3}$ stretching $\left(1100 \mathrm{~cm}^{-1}\right)$ of PVME. ${ }^{14}$ Extents of peak shifting for these two known miscible systems are reportedly small. It was of interest 
(A)

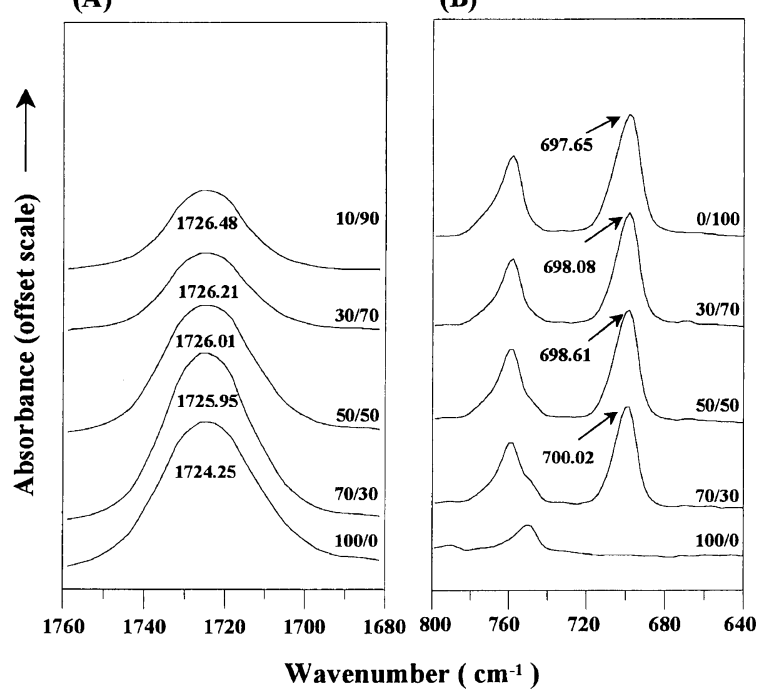

Figure 6. IR absorbance peaks of (A) the pendant carbonyl group (in PCHMA) and (B) aromatic $\mathrm{C}-\mathrm{H}$ bending (in $\mathrm{P} \alpha \mathrm{MS}$ ) for the $\mathrm{PCHMA} / \mathrm{P} \alpha \mathrm{MS}$ blends of five different compositions (wt. ratios), as indicated.

to compare the IR results to those found in other blend systems involving styrenic polymers. For the PCHMA/ $\mathrm{P} \alpha \mathrm{MS}$ system, we thus also focused on examining IR absorbance peaks of these likely sites for evidence of interactions. Figure 6 shows the IR absorbance peaks of (Diagram-A) the spectra with the carbonyl $(\mathrm{C}=\mathrm{O})$; and (Diagram-B) phenyl C-H bending: (I) neat PCHMA, and (II) PCHMA/P $\alpha$ MS blend (30/70), (III) 50/50, (IV) 70/30, and neat $\mathrm{P} \alpha \mathrm{MS}$. The absorption peak (for $\mathrm{C}=\mathrm{O}$ ) is seen at approximately $1724 \mathrm{~cm}^{-1}$ for all compositions, but the peak shifted slightly by about $2 \mathrm{~cm}^{-1}$ with changes in the composition. The minor peak shifting suggests that a relatively low level of specific interactions may be present, although it may not be significant. The polar carbonyl group of PCHMA may interact with the slightly polar phenyl ring in $\mathrm{P} \alpha \mathrm{MS}$. Absorption peaks other than the carbonyl were also examined. For examples, the spectra in the wavenumber range where the absorbance peaks of ether group $\left(1121 \mathrm{~cm}^{-1}\right)$ of PCHMA were also compared and analyzed. The peak of the ether $(\mathrm{C}-\mathrm{O}-\mathrm{C})$ group in the PCHMA polymer chain does not show significant shifting with respect to blend composition. In this PCHMA/P $\alpha$ MS blend, the phenyl $\mathrm{C}-\mathrm{H}$ bending of $\mathrm{P} \alpha \mathrm{MS}$ molecules is seen to shift slightly from $697 \mathrm{~cm}^{-1}$ for neat P $\alpha$ MS to $700 \mathrm{~cm}^{-1}$ for PCHMA/P $\alpha$ MS (70/30) blend. The shifting, however, may not be significant, and it can be viewed that the $\mathrm{C}-\mathrm{H}$ bending absorbance peak stays at about the same wavenumber regardless of composition changes. The IR result in this study shows that possible interactions between likely functional groups in P $\alpha$ MS and PCHMA are present but low or non-specific. The low level or non-specific interactions often typifies the molecular miscibility in blends comprising styrenic polymers. The FT-IR analysis suggests that relatively low intermolecular interactions, mostly non-specific, are present in the PCHMA/P $\alpha$ MS system.

\section{CONCLUSION}

Miscibility is quite rare for blends comprising styrenic polymers and acrylic/methacrylic polymers or other carbonyl-containing polymers. In this study, miscibility and phase homogeneity was discovered for the first time in the blend comprising a methacrylic polymer(PCHMA) and styrenic polymer (P $\alpha \mathrm{MS})$ in the full composition range. $\mathrm{P} \alpha \mathrm{MS}$ of a wide range of molecular weights from very low MW (several thousands) up to $400000 \mathrm{~g} \mathrm{~mol}^{-1}$ were found to be miscible with PCHMA. The miscible P $\alpha$ MS/PCHMA blend showed quite high phase separation temperatures $\left(290-320^{\circ} \mathrm{C}\right)$ upon heating, which was near the decompositions. The critical point (LCST) of phase separation upon heating was expectedly higher for the blends with lower molecular weight of $\mathrm{P} \alpha \mathrm{MS}$. Evidence of miscibility was certain from thermal analysis, optical and scanning electron microscopy characterization. Furthermore, intermolecular forces between the chain segments of these two polymers were discussed. The FT-IR result for the miscible PCHMA/P $\alpha$ MS blend suggests that the intermolecular interactions between the pairs are likely non-specific and not particularly strong. However, the average extent of interactions in the miscible PCHMA/P $\alpha$ MS blend as judged from the peak shifting is slightly greater than those in the miscible PCHMA/P4MS. ${ }^{10}$ This trend is in agreement with the that of LCST for these two systems.

Acknowledgment. This study has been sponsored by research grants provided by Taiwan's National Science Council (\#NSC 89-2216-E006-014 \& NSC 89-2216-E 006-015).

\section{REFERENCES}

1. J. Stoelting, F. E. Karasz, and W. J. MacKnight, Polym. Eng. Sci., 10, 133 (1970).

2. A. R. Shultz and B. M. Beach, Macromolecules, 7, 902 (1974).

3. W. M. Prest, Jr. and R. S. Porter, J. Polym. Sci, Part A-2, 10, 1639 (1972).

4. T. K. Kwei, T. Nishi, and R. F. Roberts, Macromolecules, 7, 667 (1974).

5. M. Bank, J. Leffingwell, and C. Thies, Macromolecules, 4, 43 (1971).

6. M. Bank, J. Leffingwell, and C. Thies, J. Polym. Sci, Part A-2, 10, 1097 (1972).

7. A. R. Shultz and A. L. Young, Macromolecules, 13, 663 (1980).

8. C. Friedrich, C. Schwarzwalder, and R.-E. Riemann, Polymer, 37, 2499 (1996).

9. M. Nishimoto, H. Keskkula, and D. R. Paul, Macromolecules, 23, 3633 (1990).

10. E. M. Woo and F. H. Jang, Polymer, 40, 3803 (1999).

11. M. Gordon and J. S. Taylor, J. Appl. Chem., 2, 493 (1952).

12. T. A. Callaghan and D. R. Paul, Macromolecules, 26, 2439 (1993).

13. E. M. Woo, T. K. Mandal, and L. L. Chang, Macromolecules, 33, 4186 (2000).

14. F. J. Lu, E. Benedetti, and S. L. Hsu, Macromolecules, 16, 1525 (1983). 